\title{
Variability in in situ ruminal degradation parameters causes imprecision in estimated ruminal digestibility
}

\author{
T. J. Hackmann, J. D. Sampson, and J. N. Spain ${ }^{1}$ \\ Division of Animal Sciences, University of Missouri, Columbia 65211
}

Key words: forage, in situ, ruminal digestibility

\section{INTRODUCTION}

Grass and legume forages are key components of ruminant diets. The quality of these forages and other components of ruminant diets is largely influenced by their digestibility (Minson, 1990), making a measure of digestibility useful in diet formulation. Because measurement of digestibility in vivo is laborious and requires large amounts of forage, digestibility is frequently estimated. Many current feed evaluation systems [e.g., Cornell Net Carbohydrate and Protein System (Sniffen et al., 1992); Molly (Baldwin, 1995); Beef NRC (NRC, 2000); Dairy NRC (NRC, 2001)] use ruminal degradation parameters (e.g., rate and extent of digestion) to estimate ruminal digestibility, which in turn is used with estimated postruminal digestion to calculate total tract digestibility. These feeding systems use simple averages of degradation parameters, such as those compiled in a feed library, to estimate ruminal digestibility. However, a limited number of sources suggest that considerable variability exists in these mean values for forages and other feeds (von Keyserlingk et al., 1996; Hvelplund and Weisbjerg, 2000; NRC, 2001). This variability raises questions about the precision of using simple averages to calculate digestibility. More work is needed to determine the actual variability in degradation parameters of forages and to ascertain whether using average values is valid. The objectives of this study were to 1 ) determine the variability in ruminal degradation parameters within and across hay forages, and 2) assess the impact of this variability on the precision of digestibility calculations.

\section{MATERIALS AND METHODS}

\section{Hay Types and Sampling Procedures}

Hay samples were obtained from entries submitted to the Missouri State Fair Hay Contest in 2002 and 2003. The entries came from across the state of Missouri and included early-cut alfalfa (ECA; $\mathrm{n}=20$ ), late-cut alfalfa $(\mathbf{L C A} ; \mathrm{n}=26)$, cool-season grass $(\mathbf{C S G} ; \mathrm{n}=11)$,

Accepted July 4, 2009.

${ }^{1}$ Corresponding author: spainj@missouri.edu 
warm-season grass (WSG; $\mathrm{n}=4$ ), and grass-legume $(\mathbf{G L} ; \mathrm{n}=20)$ samples. A detailed description of the species composition of the forages was reported in Hackmann et al. (2008). Samples were collected from hay bales by using a hay probe (Penn State Forage Sampler, Nasco, Ft. Atkinson, CO), ground through a 2-mm screen with a Wiley mill (Arthur H. Thomas Company, Philadelphia, PA), and stored in sealed plastic bags at room temperature for further analysis.

\section{In Situ and Chemical Analysis}

In situ degradation characteristics were determined for all samples. Dacron bags $(10 \times 20 \mathrm{~cm} ; 50 \pm 15$ $\mu \mathrm{m}$ pore size; Ankom Technology, Macedon, NY) were filled with $5 \pm 0.1 \mathrm{~g}$ (2003 samples) or $4 \pm 0.1 \mathrm{~g}$ (2002 samples) of sample. Duplicate bags were prepared for insertion into 2 cows, giving a total of 4 bags per sample at each incubation time.

Two ruminally cannulated, multiparous Holstein cows housed in free-stall facilities at the University of Missouri-Columbia Foremost Dairy Center were selected for in situ procedures. All procedures involving the animals were approved by the Animal Care and Use Committee, University of Missouri-Columbia. Each animal was provided ad libitum access to a lactation diet (240 g of corn silage, $123 \mathrm{~g}$ of alfalfa hay, $150 \mathrm{~g}$ of alfalfa haylage, $467 \mathrm{~g}$ of concentrate; $190 \mathrm{~g}$ of CP, $240 \mathrm{~g}$ of $\mathrm{ADF}, 410 \mathrm{~g}$ of $\mathrm{NDF} / \mathrm{kg}$ of $\mathrm{DM}$ ) formulated to meet its nutrient requirements (NRC, 2001). Bags containing 2003 hay samples were inserted into 2 cows for $0,6,12$, 24 , and $48 \mathrm{~h}$ during one 2-d period. During another 2-d period (approximately 6 mo prior), bags containing 2002 hay samples were inserted into the same 2 cows for $0,8,12,24$, and $48 \mathrm{~h}$. However, one of the cows stopped ruminating during the original sampling period for the 2002 samples, and the samples from this cow for that period were discarded. New subsamples of the 2002 hay samples were incubated in this cow for an additional 2-d period (approximately $1 \mathrm{yr}$ after the original sampling period), with incubation times of 0,6 , 12,24 , and $48 \mathrm{~h}$. Zero-hour bags were exposed to rumen fluid briefly (approximately $5 \mathrm{~min}$ ) to allow hydration. All bags were removed simultaneously, as suggested by Nocek (1988).

After removal from the rumen, bags were doused with cold water (approximately $15^{\circ} \mathrm{C}$ ) to halt fermentation and were rinsed until wash water ran relatively clear. Bags were stored at $<0^{\circ} \mathrm{C}$ to await further processing. Once removed from storage, bags were thawed to room temperature and washed in a domestic washing machine until the wash water ran completely clear, as suggested by Cherney et al. (1990). Samples were airdried in a $55^{\circ} \mathrm{C}$ convection oven to a constant mass and were then air-equilibrated and weighed to determine residue mass. Residues were then removed and composited by time within cow. Bag residue and original forage samples were ground to pass through a $1-\mathrm{mm}$ screen and subsequently analyzed for DM, NDF, ADF, hemicellulose (HEM), and CP, as described in Hackmann et al. (2008).

\section{Calculations and Statistical Analysis of In Situ Data}

All degradation data were expressed as fractional disappearance. Using an equation from Weisbjerg et al. (1990), we corrected NDF, HEM, and ADF degradation data at each incubation time for insoluble material washed out of the bag. Because NDF, ADF, and HEM are insoluble entities, it was assumed that the truly soluble fraction was zero when the equation was applied.

Aberrant bag observations were identified and eliminated using the method reported in Hackmann et al. (2008). When the criteria for eliminating aberrant bag observations were used, nearly all NDF, ADF, and HEM bag observations had to be eliminated for one 2003 ECA sample. So few bag observations were left after this elimination that NDF, ADF, and HEM degradation data could not be fitted to a model for this forage sample.

In situ data were described using a single, gamma 2-distributed pool model without a lag phase (G2), from Pond et al. (1988) and Ellis et al. (1994), as follows:

$$
Y(t)=a+b \cdot\left[1-\exp \left(-\lambda_{d} \cdot t\right) \cdot\left(1+\lambda_{d} \cdot t\right)\right],
$$

where $Y(t)$ is fractional disappearance $\left(\mathrm{g} \cdot \mathrm{g}^{-1}\right), \lambda_{d}$ is degradation rate $\left(\mathrm{h}^{-1}\right), a$ is the fraction escaping the bag and assumed degraded at $t=0\left(\mathrm{~g} \cdot \mathrm{g}^{-1}\right),(a+b)$ is the potential extent of degradation $\left(\mathrm{g} \cdot \mathrm{g}^{-1}\right), b$ is the fraction not degraded at $t=0$ that is potentially degradable $\left(\mathrm{g} \cdot \mathrm{g}^{-1}\right)$, and $t$ is time $(\mathrm{h})$. The age-dependent G2 model was chosen over the often-used age-independent models (Ørskov and McDonald, 1979) because the G2 model yielded lower values for Akaike's information criterion relative to the age-independent models, indicating the G2 model provided a fit superior to that of first-order kinetic models for this data set (see Hackmann et al., 2008).

The NLIN procedure of SAS (SAS Institute Inc., Cary, NC) was used to estimate parameters in the models for DM, NDF, ADF, HEM, and CP degradation data. Because NDF, ADF, and HEM degradation data had been corrected to make disappearance zero at $t=$ 0 , the value of $a$ was constrained to zero for fitting the procedures for these fractions. 
Most degradation rates reported in the literature are age independent, whereas $\lambda_{d}$ is an age-dependent rate (Pond et al., 1988; Ellis et al., 1994). Comparison between an age-independent rate, $k_{d}\left(\mathrm{~h}^{-1}\right)$, and an agedependent rate, $\lambda_{d}$, is not commensurate; an age-independent rate is less than an age-dependent one when describing the same degradation data. To allow for a more commensurate comparison, the mean degradation rate of $\lambda_{d}, k$, was calculated as $0.5964 \cdot \lambda_{d}$ (Pond et al., 1988). This mean rate is effectively an age-independent equivalent of an age-dependent rate and can be compared with age-independent rates commonly reported in the literature.

At first, the degradation data for each cow were kept separate for the fitting procedure. However, after a preliminary ANOVA indicated that degradation parameter values did not differ consistently across cow $\times$ period, the cow $\times$ period data were pooled by year of forage (2002 or 2003), necessitating that the data for 2 cows ( $\mathrm{n}=2$ for $2002 ; \mathrm{n}=2$ for 2003 ) be used to construct each degradation curve.

Values for standard deviations and coefficients of variation of degradation parameter estimates were calculated for each chemical fraction within a forage class. Because values for standard deviations and coefficients of variation were similar across forage classes, the values were averaged across forage classes before they were tabulated. These tabulated values should not be mistaken as standard deviations and coefficients of variation of data pooled by forage class; data were separated by forage class when values for standard deviations and coefficients of variation were calculated, and only thereafter were these values averaged.

\section{Statistical Analysis with Other Previously Published Degradation Data}

The data of Mertens (1973), von Keyserlingk et al. (1996), NRC (2001), and Hvelplund and Weisbjerg (2000) were used to calculate coefficients of variation of degradation parameter estimates for comparison with our own results. Values for coefficients of variation for $(a+b)$ and $k_{d}$ in Mertens (1973) were calculated by compiling data in the appendix of that study, which listed estimates of $(a+b)$ and $k_{d}$ individually for each experimental forage. When not reported in the original publication, values for coefficients of variation for $a, b$, and $k_{d}$ in von Keyserlingk et al. (1996) were calculated directly by using reported means and standard deviations pooled by forage class.

Because Hvelplund and Weisbjerg (2000) reported standard deviations by forage species and not by forage class, standard deviations for forage class were calculated by pooling variances of degradation parameter estimates across forage species within a class. Similarly, because the NRC (2001) reported standard deviations by forage maturity and not by forage class, standard deviations for forage class were calculated by pooling variances of degradation parameter estimates across forage maturities within a class. Variances were pooled using the equation

$$
s^{2}=\frac{\sum_{k=1}^{n}\left(n_{j}-1\right) s_{j}^{2}}{\sum_{k=1}^{n}\left(n_{j}-1\right)},
$$

where $s^{2}$ is the pooled variance, and $s_{j}^{2}$ and $n_{j}$ refer to the variance and sample size of the $j$ th forage class or maturity, respectively. Once values of standard deviations were calculated from these pooled variances, values for the coefficients of variation were then computed as with the data from von Keyserlingk et al. (1996).

\section{Calculation of Ruminal Digestibility and $95 \%$ Confidence Limits}

Predicted ruminal digestibilities of DM, ADF, HEM, and $\mathrm{CP}$ by forage class were calculated using the equation

$$
\text { digestibility }_{i, j}=a_{i, j}+b_{i, j} \frac{\lambda_{d \mid i, j}^{2}}{\left(\lambda_{d \mid i, j}+k_{p}\right)^{2}},
$$

where digestibility $_{i, j}\left(\mathrm{~g} \cdot \mathrm{g}^{-1}\right)$ is the ruminal digestibility of chemical fraction $i$ (DM, ADF, HEM, CP) and forage class $j$ (ECA, LCA, CSG, WSG, GL); $a_{i, j}$ is $a$ for chemical fraction $i$ and forage class $j ; b_{i, j}$ is $b$ for chemical fraction $i$ and forage class $j ; \lambda_{d \mid i, j}$ is $\lambda_{d}$ for chemical fraction $i$ and forage class $j$; and $k_{p}$ is the fractional rate of passage from the rumen $\left(\mathrm{h}^{-1}\right)$, set to a constant value of $0.06 \mathrm{~h}^{-1}$. This equation is conceptually analogous to the often-used equation

$$
\text { digestibility }=a+b \frac{k_{d}}{k_{d}+k_{p}},
$$

developed by Ørskov and McDonald (1979). Equations [1] and [2] are derived using the same biological principles and compute the same entity, although their precise mathematical forms differ because of the use of the age-dependent rate $\lambda_{d}$ in equation [1] in place of the independent rate $k_{d}$ in equation [2] (see the Appendix for the derivation of equation [1]). 
Upper and lower 95\% confidence limits of calculated digestibility were determined using the law of propagation of uncertainty (e.g., Taylor, 1997; Heuvelink, 1998). Frequently used in the physical and quantitative sciences, the law of propagation of uncertainty is used to compute the amount of uncertainty (analogous to standard deviation) expected in a calculated quantity (e.g., digestibility) originating from uncertainty in one or more measured quantities (e.g., $a, b, \lambda_{d}$ ) used in the calculations. In general, when a first-order Taylor approximation is used, uncertainty in a dependent variable $y$ that is a function of independent variables $x_{1}, x_{2}$, $\ldots, x_{n}$ is the following:

$$
\Delta y=\left[\sum_{k=1}^{n} \sum_{l=1}^{n}\left(\frac{\partial y}{\partial x_{k}} \frac{\partial y}{\partial x_{l}} \Delta x_{k} \Delta x_{l} \rho_{x_{k}, x_{l}}\right)\right]^{2},
$$

where $\partial y / \partial x_{k}$ and $\partial y / \partial x_{l}$ are the partial derivatives of $y$ with respect to $x_{k}$ and $x_{l}$, respectively; $\Delta x_{k}$ and $\Delta x_{l}$ are the uncertainties of $x_{k}$ and $x_{l}$, respectively; and $\rho_{x_{k} x_{l}}$ is the correlation coefficient between variables $x_{k}$ and $x_{l}$. When $k=l$, the term $\Delta x_{k} \Delta x_{l} \rho_{x_{k}, x_{l}}=\Delta x_{k}^{2}$ and when $k \neq$ $l, \Delta x_{k} \Delta x_{l} \rho_{x_{k}, x_{l}}=\sigma_{x_{k}, x_{l}}$, the covariance between $x_{k}$ and $x_{l}$; from these relations and from equations [1] and [3], the corresponding uncertainty in digestibility is expressed as

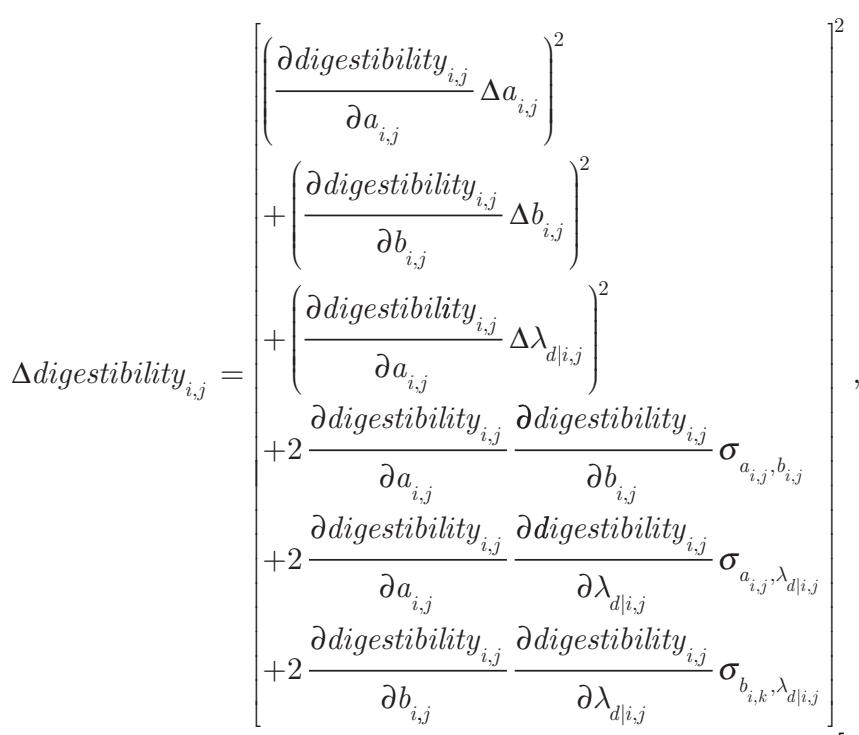

[4]

where $\Delta$ digestibility $_{i, j}$ is uncertainty in digestibility $y_{i, j}$; $\Delta a_{i, j}$ is uncertainty in $a_{i, j} ; \Delta b_{i, j}$ is uncertainty in $b_{i, j}$; $\Delta \lambda_{d \mid i, j}$ is uncertainty in $\lambda_{d \mid i, j} ; \sigma_{a_{i, j} b_{i, j}}$ is covariance between $a_{i, j}$ and $b_{i, j} ; \sigma_{a_{i, j} \lambda_{d \mid i, j}}$ is covariance between $a_{i, j}$ and $\lambda_{d \mid i, j}$; $\sigma_{b_{i, k} \lambda_{d \mid i, j}}$ is covariance between $b_{i, k}$ and $\lambda_{d \mid i, j}$; ddigestibility $i_{i, j} / \partial a_{i, j}$ is the partial derivative of digestibility $_{i, j}$ with respect to $a_{i, j}$, equal to 1 ; digestibility $_{i, j} / \partial b_{i, j}$ is the partial derivative of digestibility $_{i, j}$ with respect to $b_{i, j}$, equal to $\lambda_{d \mid i, j}^{2} /\left(\lambda_{d \mid i, j}+k_{p}\right)^{2} ;$ and digestibility $y_{i, j} / \partial \lambda_{d \mid i, j}$ is the partial derivative of digestibility ${ }_{i, j}$ with respect to $\lambda_{d \mid i, j}$, equal to

$$
2 b\left[\frac{\lambda_{d \mid i, j}}{\left(\lambda_{d \mid i, j}+k_{p}\right)^{2}}-\frac{\lambda_{d \mid i, j}^{2}}{\left(\lambda_{d \mid i, j}+k_{p}\right)^{3}}\right] .
$$

As mentioned below, the value of $\Delta k_{p}$ was set to 0 ; for simplicity, equation [4] has already been rendered with $\Delta k_{p}=0$.

Examination of equations [3] and [4] reveals the key result that increasing uncertainty in a measured quantity (e.g., degradation parameters) increases uncertainty in a calculated quantity (e.g., digestibility). This point is illustrated by Figure 1, which shows how uncertainty in $b$ translates into uncertainty in digestibility. The solid black line represents values of digestibility (computed with equation [1]) when $b$ varies from 0 to 1 (and with $a$ and $\lambda_{d}$ set to 0 and 0.075 , values similar to those for NDF of WSG). The value of $\Delta b$ is 0.08 and is centered around $b=0.60$ (values similar to those for NDF of WSG); covariances and all other uncertainties are set to 0 . As shown in Figure 1, a vertical line extending from the lower bound of $\Delta b$ on the $\mathrm{x}$-axis intersects with a horizontal line extending from the lower bound of $\Delta$ digestibility on the y-axis, where the point of intersection is a point on the graph of digestibility. A similar relationship is observed between the upper bounds of $\Delta b$ and $\Delta$ digestibility (Figure 1). As such, when $\Delta b$ is increased, $\Delta$ digestibility increases in kind. Note that the exact relationship between $b$ and digestibility shown in Figure 1 exists only when covariances and all other uncertainties are equal to 0 , but the general principle illustrated ( $\Delta$ digestibility increases with $\Delta b$ ) holds true under all conditions.

Further examination of equations [3] and [4] also reveals that increasing the partial derivative of the measured quantity relative to the calculated quantity (i.e., $\left.\partial y / \partial x_{k}\right)$ increases uncertainty, as does increasing the covariances between the measured quantities (i.e., $\left.\sigma_{x_{k}, x_{k}}\right)$.

At first, $\Delta a_{i, j}$ and $\Delta b_{i, j}$ were set to the standard deviations of $a_{i, j}$ and $b_{i, j}$ measured in the study; so too were covariances set to their measured values, to determine the composite effect of $\Delta a_{i, j}, \Delta b_{i, j}$, and $\Delta \lambda_{d / i, j}$ on 
$\Delta$ digestibility $_{i, j}$. Next, $\Delta a_{i, j}$ and $\Delta b_{i, j}$ were set to zero to study the effect of $\Delta \lambda_{d / i, j}$ on $\Delta$ digestibility $_{i, j}$ in isolation. In all analyses, the values of $\Delta \lambda_{d / i, j}$ and $\Delta k_{p}$ were set to the standard deviations of $\lambda_{d / i, j}$ and 0 , respectively.

To calculate the composite effect of $\Delta a_{i, j}, \Delta b_{i, j}$, and $\Delta \lambda_{d / i, j}$ on $\Delta$ digestibility $_{i, j}$, methods other than the law of propagation of uncertainty may be used; one alternative is to determine the digestibility of each sample by using equation [1] and then to compute the standard deviations of these digestibility values to yield $\Delta$ digestibility $_{i, j}$ when $\Delta a_{i, j}, \Delta b_{i, j}$, and $\Delta \lambda_{d / i, j}$ are equal to their standard deviations. However, only the law of propagation of uncertainty can be used for the more complex analysis in which the effect of $\Delta \lambda_{d / i, j}$ on $\Delta$ digestibility $_{i, j}$ is studied in isolation. For this reason, the law of propagation of uncertainty was used for all analyses.

Upper and lower 95\% confidence limits were computed as the quantity digestibility ${ }_{i, j} \pm \Delta$ digestibility $_{i, j} t_{0.025, n-1}$, where $t_{0.025, n-1}$ is the critical value of the right tail of the $t$ distribution with $\alpha / 2=0.025$ and with $n-1$ degrees of freedom ( $n=$ number of digestibility $i_{i, j}$ observations).

\section{RESULTS}

The chemical composition of the forages is presented in Table 1. Numerically, both alfalfa classes (ECA, LCA) had higher mean concentrations of $\mathrm{CP}$ and lower concentrations of fiber (NDF, ADF, HEM) than did grass classes (CSG, WSG). Within alfalfa, LCA had a numerically higher mean $\mathrm{CP}$ concentration and had lower fiber concentrations than did ECA. Within grasses, CSG had a numerically higher mean CP concentration and had lower fiber concentrations than did WSG.

Table 2 reports the means of degradation parameter estimates $\lambda_{d}, k, a, b$, and $(a+b)$. Mean values of $(a+$ $b$ ) of DM and $\mathrm{CP}$ were numerically higher for alfalfa (ECA, LCA) than for grass samples (CSG, WSG). Values of $(a+b)$ of fiber (NDF, ADF, HEM) were similar across classes. Mean values of $\lambda_{d}$ and $k$ were numerically higher for alfalfa (ECA, LCA) than for grasses (CSG, WSG). Within alfalfa, $\lambda_{d}$ and $k$ were higher for LCA than for ECA, and within grasses, these parameters were higher for CSG than for WSG. Differences in $\lambda_{d}$ and $k$ were consistently preserved across chemical fractions (DM, NDF, ADF, HEM, CP).

Table 3 reports the standard deviations and coefficients of variation of degradation parameter estimates $\left[\lambda_{d}, k, a, b\right.$, and $\left.(a+b)\right]$. Values in Table 3 were averaged across forage classes for brevity because standard deviations and coefficients of variation did not vary appreciably across classes. Values of standard deviations were large relative to the mean, as illustrated by large values for coefficients of variation. Values for coeffi-

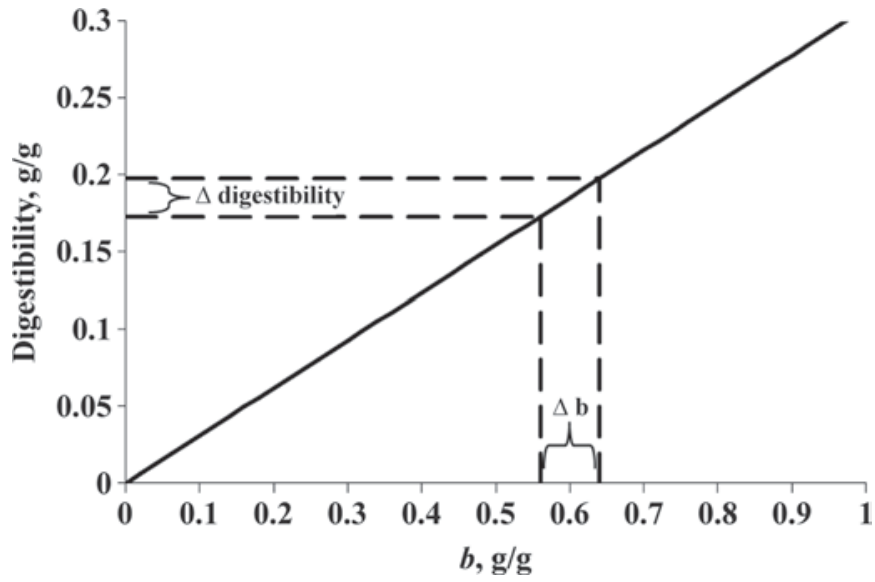

Figure 1. Graphical illustration of how increasing uncertainty in a measured quantity (e.g., degradation parameters) increases uncertainty in a calculated quantity (e.g., digestibility) according to the law of propagation of uncertainty. Digestibility (solid black line) is computed using equation [1] in the text, with $b$ [fraction not degraded at $t=0$ that is potentially degradable $\left.\left(\mathrm{g} \cdot \mathrm{g}^{-1}\right)\right]$ varying from 0 to 1 and $a$ [fraction degraded at $t=0\left(\mathrm{~g} \cdot \mathrm{g}^{-1}\right)$ ] and $\lambda_{d}$ [degradation rate $\left(\mathrm{h}^{-1}\right)$ ] held constant at 0 and 0.075 . The value of $\Delta b$ (uncertainty in $b$ ) is 0.08 and is centered around $b=0.60$, with covariances and all other uncertainties set to zero. Dashed lines mark the upper and lower bounds of $\Delta b$ and $\Delta$ digestibility (uncertainty in digestibility). The point of intersection between vertical and horizontal lines extending from the lower bounds of $\Delta b$ and $\Delta$ digestibility is a point on the graph of digestibility; a similar relationship exists between the upper bounds of the 2 variables. Increasing $\Delta b$ hence increases $\Delta$ digestibility.

cients of variation ranged from 17.3 to $36.2 \%$ for $\lambda_{d}$ and $k, 24.8$ to $32.4 \%$ for $a, 18.0$ to $23.4 \%$ for $b$, and 5.5 to $16.4 \%$ for $(a+b)$. Values for coefficients of variation for $(a+b)$ were systematically smaller than for any other parameter, whereas values for coefficients of variation for other parameters $\left(\lambda_{d}, k, a\right.$, and $\left.b\right)$ were similar in magnitude. Similarly, values for coefficients of variation for HEM were consistently larger than for any other chemical fraction, whereas coefficients of variation for CP were systematically smaller.

Table 4 shows calculated digestibility means and their associated upper and lower $95 \%$ confidence limits when $\Delta \lambda_{d}, \Delta a$, and $\Delta b$ were set to the standard deviation values of $\lambda_{d}, a$, and $b$ measured in the study. The mean digestibilities of $\mathrm{CP}$ ranged from 0.513 to 0.761 $\mathrm{g} \cdot \mathrm{g}^{-1}$ for CP. Numerically, these were generally higher than those for DM digestibility, with values of 0.406 to $0.642 \mathrm{~g} \cdot \mathrm{g}^{-1}$. These values were, in turn, numerically higher than those for NDF, ADF, and HEM, which were themselves similar, with digestibilities ranging from 0.193 to $0.288 \mathrm{~g} \cdot \mathrm{g}^{-1}$ for NDF, 0.192 to 0.270 for $\mathrm{ADF}$, and 0.217 to $0.396 \mathrm{~g} \cdot \mathrm{g}^{-1}$ for HEM.

Within ECA, the $95 \%$ confidence limits of DM and $\mathrm{CP}$ were distinct from those of NDF and ADF, and all other $95 \%$ confidence limits overlapped each other. Within LCA, the $95 \%$ confidence limits of CP digest- 
Table 1. Chemical composition of forages ${ }^{1}$

\begin{tabular}{|c|c|c|c|c|c|}
\hline Item, ${ }^{1} \mathrm{~g} \cdot \mathrm{kg} \mathrm{DM}{ }^{-1}$ & $\mathrm{n}$ & Mean & Minimum & Maximum & $\mathrm{SD}$ \\
\hline \multicolumn{6}{|l|}{ ECA } \\
\hline $\mathrm{DM}$ & 20 & 870 & 842 & 896 & 14 \\
\hline $\mathrm{NDF}$ & 20 & 431 & 329 & 502 & 45 \\
\hline $\mathrm{ADF}$ & 20 & 304 & 218 & 369 & 45 \\
\hline HEM & 20 & 127 & 95 & 184 & 28 \\
\hline $\mathrm{CP}$ & 20 & 208 & 150 & 293 & 38 \\
\hline \multicolumn{6}{|l|}{ LCA } \\
\hline DM & 26 & 859 & 825 & 880 & 15 \\
\hline $\mathrm{NDF}$ & 26 & 384 & 268 & 463 & 51 \\
\hline $\mathrm{ADF}$ & 26 & 265 & 195 & 354 & 43 \\
\hline HEM & 26 & 119 & 66 & 185 & 37 \\
\hline CP & 26 & 222 & 194 & 260 & 20 \\
\hline \multicolumn{6}{|l|}{ CSG } \\
\hline DM & 11 & 876 & 867 & 892 & 7 \\
\hline $\mathrm{NDF}$ & 11 & 658 & 452 & 772 & 81 \\
\hline $\mathrm{ADF}$ & 11 & 338 & 299 & 380 & 28 \\
\hline HEM & 11 & 320 & 123 & 392 & 73 \\
\hline $\mathrm{CP}$ & 11 & 123 & 60 & 174 & 33 \\
\hline \multicolumn{6}{|l|}{ WSG } \\
\hline DM & 4 & 867 & 845 & 886 & 17 \\
\hline $\mathrm{NDF}$ & 4 & 623 & 395 & 732 & 155 \\
\hline $\mathrm{ADF}$ & 4 & 266 & 233 & 343 & 52 \\
\hline HEM & 4 & 357 & 155 & 484 & 154 \\
\hline CP & 4 & 180 & 104 & 233 & 54 \\
\hline \multicolumn{6}{|l|}{ GL } \\
\hline DM & 20 & 868 & 819 & 890 & 18 \\
\hline $\mathrm{NDF}$ & 20 & 453 & 355 & 613 & 52 \\
\hline $\mathrm{ADF}$ & 20 & 304 & 241 & 384 & 36 \\
\hline HEM & 20 & 149 & 101 & 272 & 41 \\
\hline $\mathrm{CP}$ & 20 & 204 & 124 & 308 & 40 \\
\hline
\end{tabular}

${ }^{1} \mathrm{ECA}=$ early-cutting alfalfa; LCA = late-cutting alfalfa; $\mathrm{CSG}=$ cool-season grass; WSG = warm-season grass; $\mathrm{GL}=$ grass-legume mix; HEM = hemicellulose.

ibility were distinct from those of HEM, ADF, and NDF digestibility; the $95 \%$ confidence limits of DM digestibility were distinct from those of NDF and ADF digestibility; and all other $95 \%$ confidence limits overlapped each other. Within CSG, the 95\% confidence limits of $\mathrm{CP}$ were distinct from those of all other chemical fractions (DM, NDF, ADF, HEM), and all other 95\% confidence limits overlapped each other. Within WSG, the $95 \%$ confidence limits of DM were distinct from all other chemical fractions (NDF, ADF, HEM, $\mathrm{CP}$ ), and all other 95\% confidence limits overlapped each other. Within GL, the $95 \%$ confidence limits of $\mathrm{DM}$ and $\mathrm{CP}$ digestibility were distinct from those of $\mathrm{NDF}$ and ADF, and all other 95\% confidence limits overlapped each other.

When compared within the same chemical fraction, numerically, mean digestibilities for WSG and CSG were systematically lower than those for other forage classes, which were themselves similar to each other (Table 4). As shown in Table 4, the 95\% confidence limits for DM, NDF, ADF, HEM, and CP digestibilities overlapped each other across forage classes, with only one exception (the $95 \%$ confidence limits for DM digestibility of WSG were distinct from those of LCA).
Table 5 shows digestibility means and their associated upper and lower $95 \%$ confidence limits when $\Delta \lambda_{d}$ was set to the standard deviations of $\lambda_{d}$ measured in this study (and $\Delta a$ and $\Delta b$ were set to zero). Mean digestibilities were the same as those reported in Table 4. Within ECA, LCA, and CSG, the 95\% confidence limits of $\mathrm{CP}$ and DM digestibilities were distinct from each other and from all other chemical fractions, and the $95 \%$ confidence limits of NDF, ADF, and HEM digestibilities overlapped each other. A similar pattern was found for WSG, except that the $95 \%$ confidence limits of HEM were not distinct from those of DM. Within GL, the $95 \%$ confidence limits of CP digestibility were distinct from those of NDF, ADF, and HEM digestibilities; the $95 \%$ confidence limits of DM digestibility were distinct from those of NDF and ADF digestibilities; and all other $95 \%$ confidence limits overlapped each other.

Compared across forages, the 95\% confidence limits of DM digestibility for CSG and WSG were distinct from those for ECA, LCA, and GL. Additionally, the 95\% confidence limits for CP digestibility of WSG were distinct from those of ECA, LCA, and GL, and the 95\% confidence limits for CP digestibility of CSG were 
Table 2. Degradation parameter estimates of forages by forage class and chemical fraction

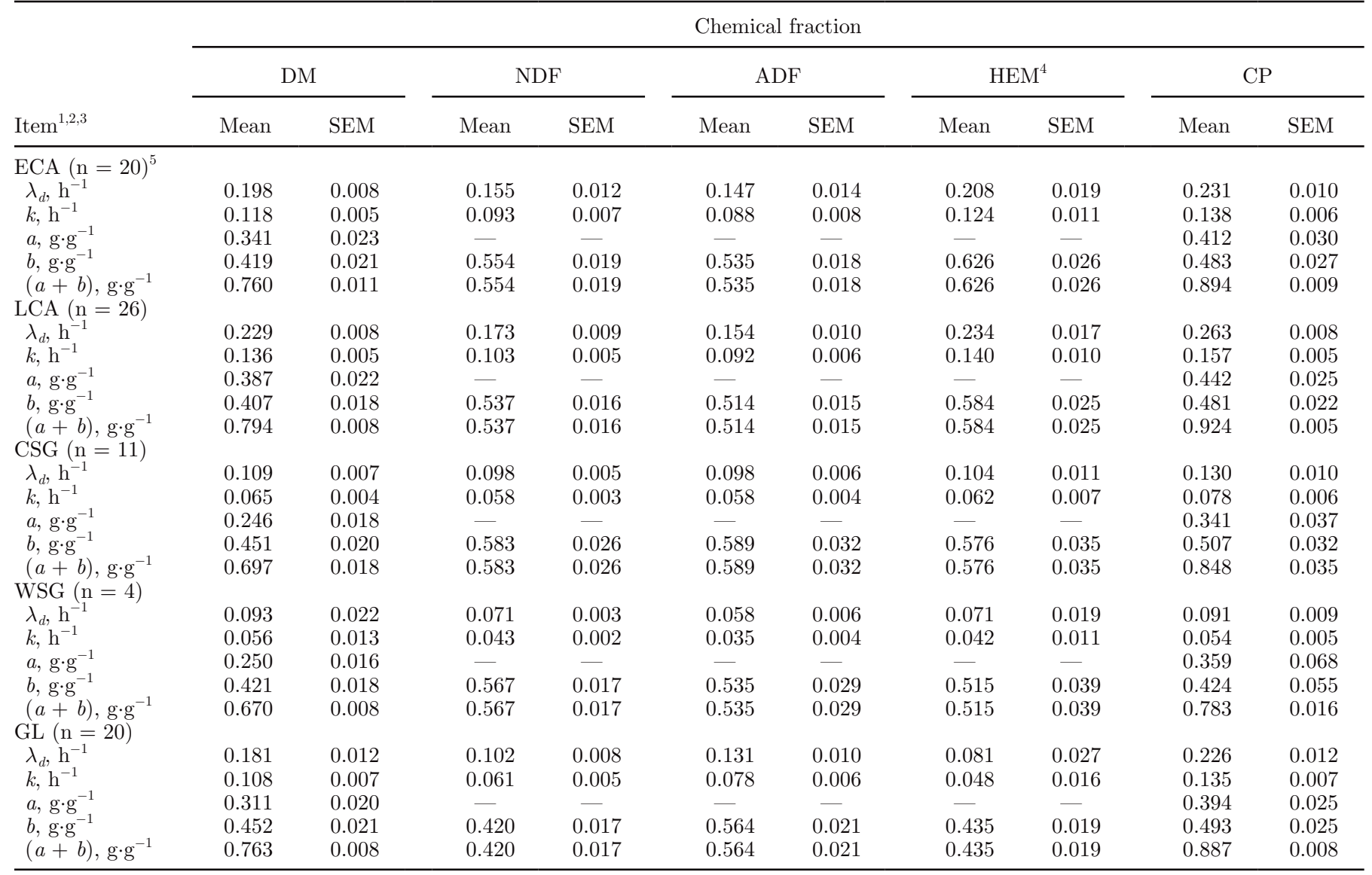

${ }^{1} \mathrm{ECA}=$ early-cutting alfalfa; LCA = late-cutting alfalfa; CSG = cool-season grass; WSG = warm-season grass; GL = grass-legume mix.

${ }^{2} k, \quad \lambda_{d}=$ degradation rate; $a=$ fraction degraded at $t=0 ;(a+b)=$ potential extent of degradation; $b=$ fraction not degraded at $t=0$ that is potentially degradable.

${ }^{3} k=0.59635 \cdot \lambda_{d}$

${ }^{4} \mathrm{HEM}=$ hemicellulose.

${ }^{5}$ Value of $\mathrm{n}$ for DM and CP. Value of $\mathrm{n}$ for NDF, ADF, and HEM is 19 because NDF, ADF, and HEM degradation data of 1 sample could not be fitted to a degradation model (see Materials and Methods section).

distinct from those of LCA. All other 95\% confidence limits of forage classes overlapped each other.

\section{DISCUSSION}

\section{Chemical Composition and Degradation Parameter Means}

The means and standard deviations of the chemical composition data in Table 1 were generally similar to those summarized by the Dairy NRC (NRC, 2001), although our samples of WSG had lower NDF, ADF, and HEM and higher CP than reported by the NRC (2001). These results suggest that a representative range of forages was included in this study. With the exception of $\lambda_{d}$ (see below), degradation parameter means in Table 2 were similar to those presented in other reports (Smith et al., 1972; Mertens, 1973; von Keyserlingk et al., 1996), indicating they were suitable for the digestibility analyses below. The values of $\lambda_{d}$ generated in this study were numerically greater than the degradation rate values reported by other investigators because $\lambda_{d}$ is an age-dependent degradation rate, whereas most degradation rates reported in the literature are ageindependent rates. For commensurate comparisons between degradation rates in this and prior studies, the mean degradation rate $k$ should be used for reference (see the Materials and Methods section).

\section{Variation in Degradation Parameter Estimates}

For comparison with values in Table 3, we summarized coefficient of variation values for degradation parameter estimates from prior studies. In the data of von Keyserlingk et al. (1996), coefficient of variation values 
Table 3. Standard deviations and CV of degradation parameter estimates, averaged by chemical fraction ${ }^{1,2}$

\begin{tabular}{|c|c|c|c|c|c|}
\hline \multirow[b]{2}{*}{ Item } & \multicolumn{5}{|c|}{ Degradation parameter } \\
\hline & $\lambda_{d}$ & $k$ & $a$ & $b$ & $(a+b)$ \\
\hline \multicolumn{6}{|l|}{ DM } \\
\hline $\mathrm{SD}$ & 0.031 & 0.019 & 0.079 & 0.077 & 0.041 \\
\hline $\mathrm{CV}, \%$ & 17.3 & 17.3 & 24.8 & 18.0 & 5.5 \\
\hline \multicolumn{6}{|l|}{$\mathrm{NDF}$} \\
\hline SD & 0.032 & 0.019 & - & 0.073 & 0.073 \\
\hline $\mathrm{CV}, \%$ & 21.7 & 21.7 & - & 12.9 & 12.9 \\
\hline \multicolumn{6}{|l|}{$\mathrm{ADF}$} \\
\hline SD & 0.038 & 0.023 & - & 0.088 & 0.088 \\
\hline $\mathrm{CV}, \%$ & 29.1 & 29.1 & - & 15.7 & 15.7 \\
\hline \multicolumn{6}{|l|}{ HEM } \\
\hline SD & 0.069 & 0.041 & - & 0.097 & 0.097 \\
\hline $\mathrm{CV}, \%$ & 36.2 & 36.2 & - & 16.4 & 16.4 \\
\hline \multicolumn{6}{|l|}{$\mathrm{CP}$} \\
\hline SD & 0.037 & 0.022 & 0.127 & 0.111 & 0.065 \\
\hline $\mathrm{CV}, \%$ & 19.7 & 19.7 & 32.4 & 23.4 & 10.1 \\
\hline
\end{tabular}

${ }^{1} k, \lambda_{d},=$ degradation rate $\left(\mathrm{h}^{-1}\right) ; a=$ fraction degraded at $t=0\left(\mathrm{~g} \cdot \mathrm{g}^{-1}\right) ;(a+b)=$ potential extent of degradation $\left(\mathrm{g} \cdot \mathrm{g}^{-1}\right) ; b=$ fraction not degraded at $t=0$ that is potentially degradable $\left(\mathrm{g} \cdot \mathrm{g}^{-1}\right)$; HEM $=$ hemicellulose.

${ }^{2}$ Values of SD and CV are averaged across forage class. Units for SD are per hour for $\lambda_{d}$ and $k$ and are gram per gram for $a, b$, and $(a+b)$.

for $a, b$, and $k_{d}$ for CP were 11.4, 20.1, and $35.1 \%$ for alfalfa hay $(\mathrm{n}=16)$ and $26.3,24.1$, and $34.9 \%$ for grass hay $(\mathrm{n}=14)$. For DM, coefficient of variation values for $a, b$, and $k_{d}$ were $7.9,7.4$, and $36.7 \%$ for alfalfa hay $(\mathrm{n}=16)$ and $16.3,25.6$, and $36.8 \%$ for grass hay $(\mathrm{n}=$ 14). In the data of Hvelplund and Weisbjerg (2000), coefficient of variation values for $a, b$, and $k_{d}$ were 11.1, 16.0 , and $27.2 \%$ for alfalfa $\mathrm{CP}(\mathrm{n}=22)$. In the same data set, coefficient of variation values for $a, b$, and $k_{d}$ were $21.8,17.6$, and $24.7 \%$ for CSG CP ( $\mathrm{n}=119)$. In the NRC (2001) data, coefficient of variation values for $a, b,(a+b)$, and $k_{d}$ were $34.8,32.2,11.2,46.5 \%$ for alfalfa CP $(\mathrm{n}=83)$. In the same data set, coefficient of variation values for $a, b,(a+b)$, and $k_{d}$ were 22.7 , 20.4, 4.8, and 35.5\% for CSG CP $(\mathrm{n}=113)$. In Mertens (1973), coefficient of variation values for $(a+b)$ and $k_{d}$ for NDF were 18.1 and $21.5 \%$ for alfalfa $(\mathrm{n}=40), 14.8$ and $19.6 \%$ for GL, 10.9 and 29.3 for CSG $(\mathrm{n}=171)$, and 12.8 and $25.5 \%$ for WSG $(\mathrm{n}=8)$.

In sum, the literature values for coefficients of variation for $a$ ranged from 7.9 to $34.8 \%$, those for $b$ ranged from 7.4 to $32.2 \%$, those for $(a+b)$ ranged from 4.8 to 18.1 , and those for $k_{d}$ ranged from 19.6 to $36.5 \%$, with no clearly detectable differences across forage classes (alfalfa, GL, CSG, WSG) or chemical fractions (DM, $\mathrm{CP}, \mathrm{NDF}$ ). Coefficient of variation values for DM, CP, and NDF in our own data set (Table 3) generally fell within these ranges. The large amount of variability we found in degradation parameter values is thus reasonable. Note that in prior reports, coefficient of variation values for degradation rate were larger than those for other parameters, unlike in this experiment.
In general, the variation in degradation parameter estimates was due to a combination of 1 ) variation truly attributable to the chemical fraction and forage class and 2) procedural variation. For in situ studies (such as the current one), common sources of procedural variation arise from factors such as bag characteristics (material, size, pore size, sample size to surface area), sample preparation (grind size), incubation procedure (presence or absence of preincubation, reticuloruminal region in which bags are incubated, incubation times, order of bag removal and insertion), replications (number of animals, days, and bag replications), rinsing technique (hand vs. mechanical rinsing), and animal-related parameters (species, diet, temporal and individual variation in the reticulorumen environment; Nocek, 1988; Vanzant et al., 1998). Most of these factors (bag characteristics, sample preparation, incubation technique, rinsing technique, animal species, diet) were controlled in this study by adopting a standardized procedure. Other sources of variation, such as variation among animals, days, and replicate bags (Mehrez and Ørskov, 1977; Vanzant et al., 1998) were reduced by using multiple animals ( 2 per forage) and bags ( 2 per animal).

Although an extensive effort was made to minimize procedural error relative to variation attributable to chemical fraction and forage class, procedural error may still have been appreciable. In this context, it is difficult to explain systematic differences in coefficients of variation across degradation parameters and chemical fractions because these differences are confounded by the 2 sources of variation defined above. For example, the 
Table 4. Calculated digestibility of chemical fractions by forage class and upper and lower $95 \%$ confidence limits (CL), using uncertainty values of $\lambda_{d}, a$, and $b$ equal to their $\mathrm{SD}^{1,2}$

\begin{tabular}{|c|c|c|c|c|c|}
\hline \multirow[b]{2}{*}{ Item, $g \cdot g^{-1}$} & \multicolumn{5}{|c|}{ Forage class } \\
\hline & ECA & LCA & CSG & WSG & GL \\
\hline \multicolumn{6}{|l|}{$\mathrm{DM}$} \\
\hline Digestibility $^{3}$ & $0.588^{\mathrm{a}}$ & $0.642^{\mathrm{ab}}$ & $0.436^{\mathrm{ab}}$ & $0.406^{\mathrm{a}}$ & $0.570^{\mathrm{a}}$ \\
\hline Lower $95 \%$ CL & 0.456 & 0.508 & 0.301 & 0.324 & 0.434 \\
\hline \multirow{2}{*}{\multicolumn{6}{|c|}{ NDF }} \\
\hline & & & & & \\
\hline Digestibility $^{3}$ & $0.288^{\mathrm{b}}$ & $0.296^{\mathrm{c}}$ & $0.225^{\mathrm{b}}$ & $0.193^{\mathrm{b}}$ & $0.296^{\mathrm{b}}$ \\
\hline Lower $95 \%$ CL & 0.157 & 0.177 & 0.113 & 0.123 & 0.192 \\
\hline Upper $95 \%$ CL & 0.420 & 0.415 & 0.337 & 0.264 & 0.401 \\
\hline \multicolumn{6}{|l|}{$\mathrm{ADF}$} \\
\hline Digestibility $^{3}$ & $0.270^{\mathrm{b}}$ & $0.266^{\mathrm{c}}$ & $0.226^{\mathrm{b}}$ & $0.192^{\mathrm{b}}$ & $0.266^{\mathrm{b}}$ \\
\hline Lower 95\% CL & 0.123 & 0.167 & 0.114 & 0.120 & 0.158 \\
\hline Upper $95 \%$ CL & 0.417 & 0.366 & 0.338 & 0.263 & 0.374 \\
\hline \multicolumn{6}{|l|}{ HEM } \\
\hline Digestibility $^{3}$ & $0.377^{\mathrm{ab}}$ & $0.370^{\mathrm{bc}}$ & $0.231^{\mathrm{ab}}$ & $0.217^{\mathrm{ab}}$ & $0.396^{\mathrm{ab}}$ \\
\hline Lower $95 \%$ CL & 0.174 & 0.134 & 0.107 & 0.045 & 0.170 \\
\hline Upper $95 \%$ CL & 0.581 & 0.606 & 0.355 & 0.389 & 0.623 \\
\hline \multicolumn{6}{|l|}{$\mathrm{CP}$} \\
\hline Digestibility $^{3}$ & $0.716^{\mathrm{a}}$ & $0.761^{\mathrm{a}}$ & $0.597^{\mathrm{a}}$ & $0.513^{\mathrm{ab}}$ & $0.702^{\mathrm{a}}$ \\
\hline Lower $95 \%$ CL & 0.544 & 0.640 & 0.348 & 0.240 & 0.573 \\
\hline Upper $95 \%$ CL & 0.877 & 0.882 & 0.847 & 0.787 & 0.831 \\
\hline \multicolumn{6}{|c|}{${ }^{\mathrm{a}-\mathrm{c}}$ Means with different superscripts within column have nonoverlapping 95\% CL. } \\
\hline \multicolumn{6}{|c|}{$\begin{array}{l}{ }^{1} \lambda_{d}=\text { degradation rate }\left(\mathrm{h}^{-1}\right) ; a=\text { fraction degraded at } t=0\left(\mathrm{~g} \cdot \mathrm{g}^{-1}\right) ; b=\text { fraction not degraded at } t=0 \text { tha } \\
\text { is potentially degradable }\left(\mathrm{g} \cdot \mathrm{g}^{-1}\right) ;(a+b)=\text { potential extent of degradation; ECA = early-cut alfalfa; LCA }= \\
\text { late-cut alfalfa; CSG = cool-season grass; WSG = warm-season grass; GL = grass-legume mixture; HEM = } \\
\text { hemicellulose. }\end{array}$} \\
\hline
\end{tabular}

consistently smaller coefficients of variation for $(a+$ b) compared with other degradation parameters could be caused by lower measurement error because of some feature of the procedure, or by lower true variation in this parameter across chemical fractions and forages, or both. Whatever its source, variation in degradation parameters was substantial and was comparable with studies using a wide range of in situ and in vitro methodologies.

\section{Calculated Digestibilities and Their 95\% Confidence Limits}

Many feed analysis systems [e.g., Cornell Net Carbohydrate and Protein System (Sniffen et al., 1992); Molly (Baldwin, 1995); Beef NRC (NRC, 2000); Dairy NRC (NRC, 2001)] use degradation parameter estimate means to calculate ruminal digestibility or TDN. Because of the considerable variability in degradation rate and other degradation parameter estimates, as discussed above, the precision in using simple means may be questioned. To determine variability in ruminal digestibility calculated by using mean values, the $95 \%$ confidence limits of digestibility were computed by using the law of propagation of uncertainty.
Values in Table 4 (where $\lambda_{d}, a$, and $b$ equal their standard deviations) represent the case in which digestibility is calculated from estimated $a, b$, and $\lambda_{d}$ means, such as those from a feed library. The $95 \%$ confidence limits of digestibility means in Table 4 frequently overlapped each other, both within and across forage classes, even when there were large numerical differences between the means. As may be anticipated by their frequent overlapping, the $95 \%$ confidence limits spanned a wide range of values, equal to $80.5 \%$ of their associated digestibility means on average. These findings, together with those discussed above, suggest that digestibility values calculated by using mean values of $a, b$, and $\lambda_{d}$ may have limited practical and biological meaning.

In Tables 4 and 5, we indicate which $95 \%$ confidence limits overlapped, mainly to illustrate the width of the $95 \%$ confidence limits, rather than to report the results of a formal pair-wise test of digestibility means. We did not use a suitable methodology for pair-wise comparison of digestibility means (notably, a Tukey or Bonferroni correction for multiple comparisons), and it is inappropriate to interpret the results above as such comparisons.

Note that $k_{p}$ and chemical composition of the forages were assumed to have no uncertainty - that is, there 
Table 5. Calculated digestibility of chemical fractions by forage class and upper and lower $95 \%$ confidence limits (CL), using uncertainty values of $\lambda_{d}$ equal to its $\mathrm{SD}^{1,2}$

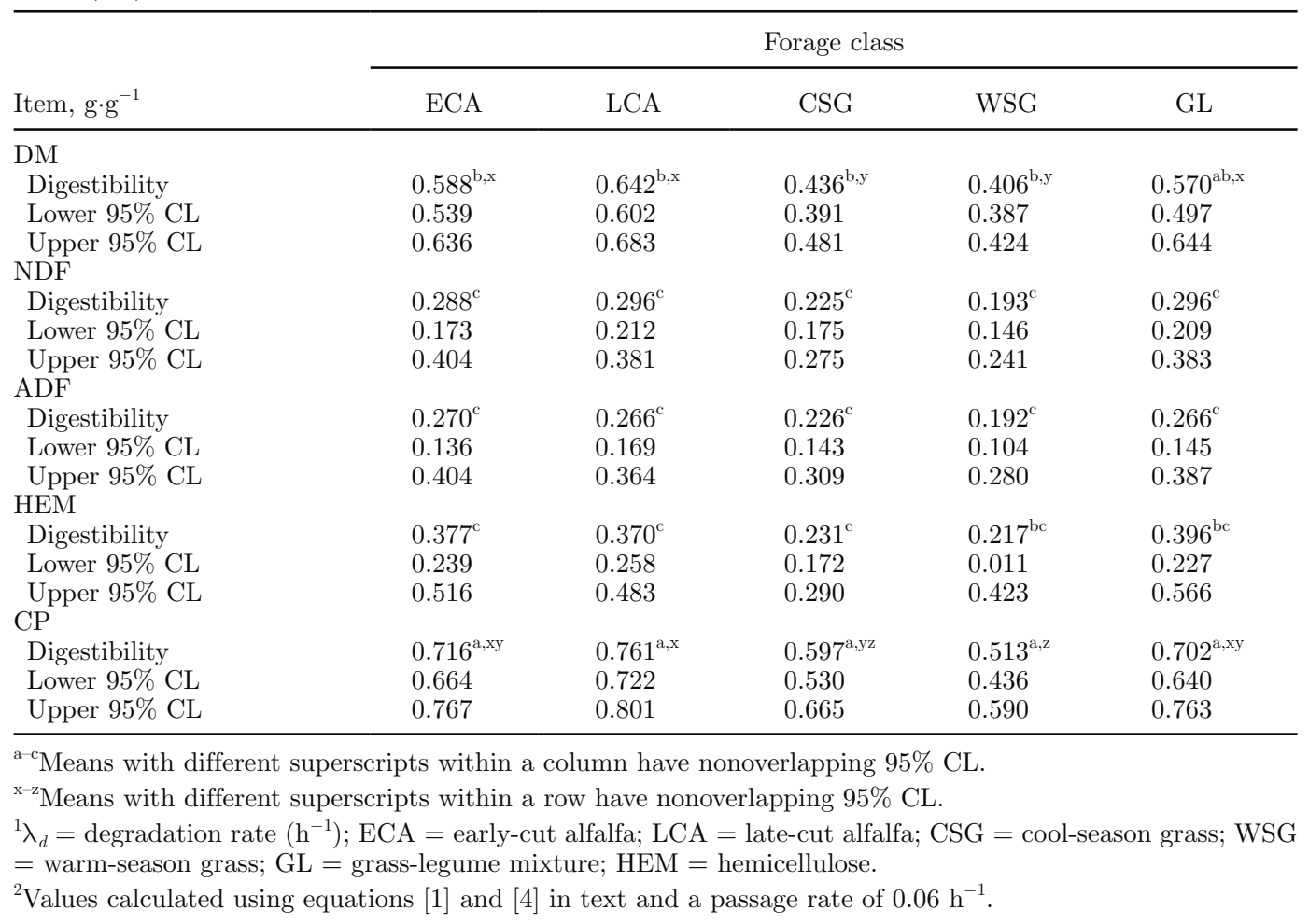

was assumed to be no error in their estimation. Because there was considerable variability in $k_{p}$ and because published equations predict $k_{p}$ with low precision [the best equation for predicting $k_{p}$ of forages in Seo et al. (2006) had a root mean square prediction error of 0.011 $\mathrm{h}^{-1}$ with $\left.\mathrm{R}^{2}=0.39\right], 95 \%$ confidence limits would be much greater in more practical cases (e.g., in which $k_{p}$ was not known and thus had to be estimated) than in Table 4, where it is assumed to be known with certainty. In all likelihood, the $95 \%$ confidence limits reported in Table 4 are greatly underestimated. This result further cautions against using the mean values of $a, b$, and $\lambda_{d}$ to calculate digestibility.

\section{Analysis Where a and b Are Known with Certainty}

Values of $a$ and $b$ may often be measured or estimated readily by using solubility and chemical assays, such as buffer-soluble N (Krishnamoorthy et al., 1983), which is used to estimate $a$ for $\mathrm{CP}$, and lignin, which is used to predict $b$ for NDF (Smith et al., 1972; Mertens, 1973; Traxler et al., 1998). To mimic cases in which $a$ and $b$ are measured, the $95 \%$ confidence limits were recalculated, assuming that $a$ and $b$ were known with certainty and that $\lambda_{d}$ alone had uncertainty (Table 5).

The $95 \%$ confidence limits in Table 5 overlapped each other less frequently than those in Table 4, compared both within and across forage classes. However, con- siderable variation in calculated digestibility was still present when $a$ and $b$ were known with certainty. On average, $95 \%$ confidence limits encompassed values $54.4 \%$ of their associated digestibility means. This percentage was less than when $a$ and $b$ were uncertain (80.5\%), but it was still large enough to limit the practical and biological meaning of the calculated digestibilities.

As discussed above, $k_{p}$ of the forages were assumed to have no uncertainty; thus, the $95 \%$ confidence limits listed in Table 5 are likely to be smaller than realized when $k_{p}$ must be estimated. Note also that it is unrealistic to assume values of $a$ and $b$ with absolute certainty, as was done in calculating the $95 \%$ confidence limits reported in Table 5. At the very least, analytical error in measuring $a$ and $b$ contributes uncertainty to the values of these parameters. Further, $a$ and $b$ cannot be measured directly but must be estimated from another chemical or physical measurement; for example, $b$ of NDF is often estimated from lignin content of the NDF (Smith et al., 1972; Mertens, 1973; Traxler et al., 1998); errors in this estimation add uncertainty. Overall, because of these sources of uncertainty that were not accounted for in the calculations in this report, the widths of the $95 \%$ confidence limits in Table 5 are likely underestimated.

Here and throughout, one may attribute the large $95 \%$ confidence limits we found to some suspected peculiarity in our in situ procedure, kinetic model (equa- 
tion [1]), uncertainty analysis (equation [4]), or some other aspect of our methodology. One may also suggest that our 95\% confidence limits are inflated because sample sizes for some forage classes were limited (n $=4$ for WSG). We reemphasize that the amount of variability in degradation parameter values we found was comparable with that of in vitro and other in situ studies using a wide range of methodologies, including those studies using very large sample sizes $(\mathrm{n}>100$; Mertens, 1973; Hvelplund and Weisbjerg, 2000; NRC, 2001). Although we carried out the uncertainty analysis fully with our parameter values alone, we would expect similarly large $95 \%$ confidence limits when using values from other reports because of this comparable variability (cf., Figure 1 and the Materials and Methods section). Although largely foreign to the animal and nutritional sciences, the uncertainty analysis we used is itself well accepted in the physical sciences. The large 95\% confidence limits we found were thus not artifacts of the conditions of our study.

These results caution against using the mean degradation parameter values to estimate digestibility. As a corollary, caution should be exercised when using digestibility values garnered from feed analysis systems that rely on approaches to calculate digestibility similar to those used in this report. Because uncertainty in $\lambda_{d}$ contributes appreciable uncertainty in calculated digestibility, techniques to measure or effectively estimate $\lambda_{d}$ efficiently should continue to be developed. One promising approach is that proposed by Van Soest et al. (2000), who developed multiple regression equations that can accurately estimate the degradation rate of forage NDF from chemical composition and in vitro digestibility. The data set from this study could be used to further validate the equations of Van Soest et al. (2000) and to formulate similar equations for non-NDF chemical fractions.

\section{REFERENCES}

Baldwin, R. L. 1995. Modeling Ruminant Digestion and Metabolism. Chapman and Hall, London, UK.

Cherney, D. J. R., J. A. Patterson, and R. P. Lemenager. 1990. Influence of in situ bag rinsing technique on determination of dry matter disappearance. J. Dairy Sci. 73:391-397.

Ellis, W. C., J. H. Matis, T. M. Hill, and M. R. Murphy. 1994 Methodology for estimating digestion and passage kinetics of forages. Pages 682-753 in Forage Quality, Evaluation, and Utilization. G. C. Fahey Jr., M. Collins, D. R. Mertens, and L. E. Moser, ed. Am. Soc. Agron., Crop Sci. Soc. Am., Soil Sci. Soc. Am., Madison, WI.

Hackmann, T. J., J. D. Sampson, and J. N. Spain. 2008. Comparing relative feed value with degradation parameters of grass and legume forages. J. Anim. Sci. 86:2344-2356.

Heuvelink, G. B. M. 1998. Error Propagation in Environmental Modelling with GIS. Taylor and Francis, Bristo, PA.

Hvelplund, T., and M. R. Weisbjerg. 2000. In situ techniques for the estimation of protein degradability and postrumen availability. Pages $233-258$ in Forage Evaluation in Ruminant Nutrition. D.
I. Givens, E. Owen, R. F. E. Axford, and H. M Omed, ed. CABI, Wallingford, UK.

Krishnamoorthy, U., C. J. Sniffen, M. D. Stern, and P. J. Van Soest. 1983. Evaluation of a mathematical model of rumen digestion and an in vitro simulation of rumen proteolysis to estimate the rumen-undegraded nitrogen content of feedstuffs. Br. J. Nutr. 50:555-568.

Mehrez, A. Z., and E. R. Ørskov. 1977. A study of the artificial fibre bag technique for determining the digestibility of feeds in the rumen. J. Agric. Sci. 88:645-650.

Mertens, D. R. 1973. Application of theoretical mathematical models to cell wall digestion and forage intake in ruminants. PhD Diss. Cornell Univ., Ithaca, NY.

Minson, D. J. 1990. Forage in Ruminant Nutrition. Academic Press, New York.

Nocek, J. E. 1988. In situ and other methods to estimate ruminal protein and energy digestibility: A review. J. Dairy Sci. 71:20512069 .

NRC. 2000. Nutrient Requirements of Beef Cattle. 7th updated ed. Natl. Acad. Press, Washington, DC.

NRC. 2001. Nutrient Requirements of Dairy Cattle. 7th rev. ed. Natl. Acad. Press, Washington, DC.

Ørskov, E. R., and I. McDonald. 1979. The estimation of protein degradability in the rumen from incubation measurements weighted according to rates of passage. J. Agric. Sci. 92:499-503.

Pond, K. R., W. C. Ellis, J. H. Matis, H. M. Ferreiro, and J. D. Sutton 1988. Compartment models for estimating attributes of digesta flow in cattle. Br. J. Nutr. 60:571-595.

Seo, S., L. O. Tedeschi, C. G. Schwab, C. Lanzas, and D. G. Fox. 2006 Development and evaluation of empirical equations to predict feed passage rate in cattle. Anim. Feed Sci. Technol. 128:67-83.

Smith, L. W., H. K. Goering, and C. H. Gordon. 1972. Relationships of forage compositions with rates of cell wall digestion and indigestibility of cell walls. J. Dairy Sci. 55:1140-1147.

Sniffen, C. J., J. D. O'Connor, P. J. Van Soest, D. G. Fox, and J. B. Russell. 1992. A net carbohydrate and protein system for evaluating cattle diets: II. Carbohydrate and protein availability. J. Anim. Sci. 70:3562-3577.

Taylor, J. R. 1997. An Introduction to Error Analysis: The Study of Uncertainties in Physical Measurements. 2nd ed. University Science Books, Sausalito, CA.

Traxler, M. J., D. G. Fox, P. J. Van Soest, A. N. Pell, C. E. Lascano, D. P. Lanna, J. E. Moore, R. P. Lana, M. Velez, and A. Flores. 1998. Predicting forage indigestible NDF from lignin concentration. J. Anim. Sci. 76:1469-1480.

Van Soest, P. J., M. E. Van Amburgh, and L. O. Tedeschi. 2000 Rumen balance and rates of fiber digestion. Pages 150-166 in Proc. Cornell Nutr. Conf. Feed Manuf. Cornell University, Ithaca, NY.

Vanzant, E. S., R. C. Cochran, and E. C. Titgemeyer. 1998 Standardization of in situ techniques for ruminant feedstuff evaluation. J. Anim. Sci. 76:2717-2729.

von Keyserlingk, M. A. G., M. L. Swift, R. Puchala, and J. A. Shelford. 1996. Degradability characteristics of dry matter and crude protein of forages in ruminants. Anim. Feed Sci. Technol. 57:291-311.

Weisbjerg, M. R., P. K. Bhargava, T. Hvelplund, and J. Madsen. 1990. Anvendelse af nedbrydningsprofiler i fodermiddelvurderingen. Beret. Statens Husdyrbrugsfors. Report no. 679. National Institute of Animal Science, Foulum, Denmark.

\section{APPENDIX}

Digestibility is the sum of $a_{i, j}$ and $b_{i, j}$ that is digested in the rumen:

$$
\text { digestibility }_{i, j}=a_{i, j}{ }^{\prime}+b_{i, j}{ }^{\prime}
$$

where $a_{i, j}{ }^{\prime}$ and $b_{i, j}{ }^{\prime}$ are $a_{i, j}$ and $b_{i, j}$ that is digestible $\left(\mathrm{g} \cdot \mathrm{g}^{-1}\right)$. The terms $a_{i, j}{ }^{\prime}$ and $b_{i, j}{ }^{\prime}$ are explicitly defined as 


$$
a_{i, j}{ }^{\prime}=p_{a_{i, j}} \cdot a_{i, j},
$$

and

$$
b_{i, j}{ }^{\prime}=p_{b_{i, j}} \cdot b_{i, j},
$$

where $p_{a_{i, j}}$ and $p_{b_{i, j}}$ are the fractions $\left(\mathrm{g} \cdot \mathrm{g}^{-1} ; a_{i, j}\right.$ or $\left.b_{\mathrm{i}, \mathrm{j}}\right)$ of $a_{i, j}$ and $b_{i, j}$ that are digestible. It is assumed that the $a_{i, j}$ fraction is completely digestible (i.e., $p_{a_{i, j}}=1$ ), following its definition that it is instantly degraded. For the G2 model used in this report, $p_{b_{i, j}}$ is equal to

$$
p_{b_{i, j}}=\frac{\lambda_{d \mid i, j}^{2}}{\left(\lambda_{d \mid i, j}+k_{p}\right)^{2}} \text {. }
$$

This follows from the definition of fractional digestibility as the amount of material (in this case, $b_{i, j}$ ) that disappears by digestion divided by its total disappearance; mathematically, this is equivalent to the integral (over the interval $t=0$ to infinity) of $r_{i, j}(t)$, the rate function for digestion of $b_{i, j}\left(\mathrm{~h}^{-1}\right)$, multiplied by $B_{i, j}(t)$, the amount of $b_{i, j}$ remaining over time $\left(\mathrm{g} \cdot \mathrm{g}^{-1} ; b_{i, j}\right)$ :

$$
p_{b_{i, j}}=\int_{t=o}^{\infty}\left[r_{i, j}(t) \cdot B_{i, j}(t)\right] d t=\frac{\lambda_{d \mid i, j}^{2}}{\left(\lambda_{d \mid i, j}+k_{p}\right)^{2}} .
$$

[For a G2 model, $r_{i, j}(t)$ is

$$
r_{i, j}(t)=\frac{\lambda_{d \mid i, j}^{2} \cdot t}{1+\lambda_{d \mid i, j} \cdot t}
$$

(Pond et al., 1988; Ellis et al., 1994) and the term $B_{i, j}(t)$

$$
B_{i, j}(t)=\left(1+\lambda_{d \mid i, j} \cdot t\right) \exp \left[-t \cdot\left(\lambda_{d \mid i, j}+k_{p}\right)\right],
$$

is the solution to the differential equation that describes the change of $B_{i, j}(t)$ over time by digestion and passage:

$$
\left.\frac{d B_{i, j}(t)}{d t}=-\left[r_{i, j}(t)+k_{p}\right] B_{i, j}(t) .\right]
$$

Making the appropriate substitutions, the final digestibility equation (equation [1] in the text) is then

$$
\text { digestibility }_{i, j}=a_{i, j}+b_{i, j} \frac{\lambda_{d \mid i, j}^{2}}{\left(\lambda_{d \mid i, j}+k_{p}\right)^{2}} .
$$

